\title{
Insect Behavior and Physiological Adaptation Mechanisms Under Starvation Stress
}

\author{
Dao-Wei Zhang*, Zhong-Jiu Xiao, Bo-Ping Zeng, Kun Li and Yan-Long Tang \\ School of Biological and Agricultural Science and Technology, Zunyi Normal University, Zunyi, China
}

Intermittent food shortages are commonly encountered in the wild. During winter or starvation stress, mammals often choose to hibernate while insects-in the form of eggs, mature larvae, pupae, or adults opt to enter diapause. In response to food shortages, insects may try to find sufficient food to maintain normal growth and metabolism through distribution of populations or even migration. In the face of hunger or starvation, insect responses can include changes in behavior and/or maintenance of a low metabolic rate through physiological adaptations or regulation. For instance,

OPEN ACCESS

Edited by:

Su Wang,

Beijing Academy of Agricultural and Forestry Sciences, China

Reviewed by: Leena Thorat, Savitribai Phule Pune University, India Shoaib Freed, Bahauddin Zakariya University,

Pakistan

*Correspondence:

Dao-Wei Zhang zhangdw1000@163.com

Specialty section:

This article was submitted to Invertebrate Physiology, a section of the journal

Frontiers in Physiology

Received: 23 September 2018 Accepted: 11 February 2019 Published: 05 March 2019

Citation:

Zhang D-W, Xiao Z-J, Zeng B-P,

LiK and Tang Y-L (2019) Insect Behavior and Physiological Adaptation Mechanisms Under Starvation Stress.

Front. Physiol. 10:163. doi: 10.3389/fphys.2019.00163 in order to maintain homeostasis of the blood sugar, trehalose under starvation stress, other sugars can be transformed to sustain basic energy metabolism. Furthermore, as the severity of starvation increases, lipids (especially triglycerides) are broken down to improve hunger resistance. Starvation stress simultaneously initiates a series of neural signals and hormone regulation processes in insects. These processes involve neurons or neuropeptides, immunity-related genes, levels of autophagy, heat shock proteins and juvenile hormone levels which maintain lower levels of physiological metabolic activity. This work focuses on hunger stress in insects and reviews its effects on behavior, energy reserve utilization, and physiological regulation. In summary, we highlight the diversity in adaptive strategies of insects to hunger stress and provides potential ideas to improve hunger resistance and cold storage development of natural enemy insects. This gist of literature on insects also broadens our understanding of the factors that dictate phenotypic plasticity in adjusting development and life histories around nutritionally optimal environmental conditions.

Keywords: insect, starvation stress, behavior, trehalose, physiological adaptation, ecological regulation

\section{INTRODUCTION}

Food is a critical source of nutrients and an important external factor in insect survival. Lack of food over long periods of time affects the growth and reproduction of insects and may even result in death (Chang, 2015; Yang et al., 2016). However, insects can enter an anti-stress state to adapt to adverse conditions. Diapause, a decrease in metabolism, and increased lipid deposition help insects to adapt to food shortages and maintain homeostasis and recover once favorable conditions return (Sánchez-Paz et al., 2006; Buckemüller et al., 2017; McCue et al., 2017). Insects can enter diapause in the form of eggs, mature larvae, pupae or adults to survive the long and resourcescarce winter (Zhang X. Y. et al., 2015). In addition to natural seasonal changes, damage to the 
ecological environment can often lead to food shortages and is one of the most common and severe stresses in nature (Panizzi and Hirose, 1995; Rotkopf et al., 2013). Previous studies have found that insect responses to food deficiencies or hunger stress generally fall into one of the two categories: (1) behavioral activities, i.e., ecological adaptation strategies whereby insects find food-rich places through behaviors such as migration or other activities such as entry into diapause, etc. or (2) physiological countermeasures that regulate the metabolism of related physiological and biochemical substances in the body to improve the insect's ability to endure hunger (Yang et al., 2016). Since food availability is crucial for insect survival, studying the consequences associated with starvation stress helps reveal adaptive strategies. Understanding these strategies is useful for the storage and release of natural insect enemies for biological pest control (Fujikawa et al., 2009). Previous reviews have summarized insect tolerance to starvation and hunger regulation mechanisms such as physiological adaptations to sugar intake (Chng et al., 2017), neurohormone adaptation (Perić-Mataruga, 2006) and diapause (Hahn and Denlinger, 2007). Here we review studies of insect behavioral and physiological adaption mechanisms under starvation, especially those involving energy changes between carbohydrates, lipids, and proteins, as well as nerve signals and hormone regulation.

\section{REGULATION OF INSECT BEHAVIOR UNDER STARVATION}

Under the stress of starvation, insects tend to change their behavior that includes migration, cannibalism, early entry into diapause or the pupal stage, and reduced numbers of eggs (Table 1). For example, when larvae of Drosophila melanogaster (Diptera: Drosophilidae) and Harmonia axyridis (Coleoptera: Coccinellidae) are nutritionally challenged, they exhibit cannibalistic behavior (Ahmad et al., 2015). The main behavioral responses toward seasonal food shortages are migration and diapause. The rate at which larvae secrete ecdysteroids is significantly increased because hunger affects the level and production of ecdysone (Chen and $\mathrm{Gu}, 2006$ ). Thus, larvae enter the pupal stage earlier under starvation conditions and the duration of pupation is prolonged with increasing days of starvation (Ballard et al., 2008). Moreover, pupae are very resistant so many insects endure adverse environmental conditions in the pupal form (Zhang X. Y. et al., 2015). For example, the larvae of Psacothea hilaris (Coleoptera: Cerambycidae) reach the pupal stage early after fasting (Munyiri and Ishikawa, 2005; Helm et al., 2017). When food is scarce, some beetles begin metamorphosis earlier (Zauner et al., 2000) while Bactrocera dorsalis (Diptera: Tephritidae) larvae enter the pupal stage after $12 \mathrm{~h}$ of starvation (Cong et al., 2015).

Insufficient food also limits insect reproduction (Zhang H. H. et al., 2015; Ojima et al., 2018). The most typical survival mechanism is to reduce reproductive investment under starvation conditions to increase somatic cell maintenance (Elkin and Reid, 2005; García-Roger et al., 2006; Billings et al., 2018). Studies of Bactrocera minax (Diptera: Tephritidae) indicated that hunger was not conducive to ovary development and led to a significant reduction in the number of matings and egg production and a prolonged spawning period (Huang, 2015). Similarly, under starvation conditions, Arma chinensis (Hemiptera: Pentatomidae) reduced the number of eggs laid and also exhibited a decline in the hatching rate of eggs (Zhang et al., 2017). Compared with bees kept under normal environmental conditions, the ovaries of hungry Apis mellifera (Hymenoptera: Apidae) worker bees showed shrinkage and decrease in egg plaques (Wang et al., 2016a,b). These behavioral adjustments are aimed at limiting population size to ensure availability of sufficient food for the existing population. However, there are exceptions. In the case of Eriosoma lanigerum (Hemiptera: Aphididae), the early stages of starvation produced a large number of breeding individuals followed by a sharp decline with progressive duration of starvation. In this way, the production of future generations was prioritized and then their own life processes were maintained (Chen, 2013).

In nature, most insects enter diapause during winter food shortages. However, a small number of insects migrate to places more suitable for growth and reproduction. After the low temperatures and food shortage conditions are over, they return to their original habitats to continue normal survival and growth (Feng et al., 2014). For example, in the fall in China, Mythimna separata (Lepidoptera: Noctuidae) moves from high to low altitudes and latitudes for the winter (Li, 1993). Incompletely metamorphosed insects that do not experience the pupal stage seek food by moving. It must be noted that hunger stress can also affect the ability of insects to take off and fly. Hunger before flight can have a negative impact on flight endurance (Kehl and Fischer, 2012), for instance, the speed and angular velocity of beetles decrease with increasing hunger (Nguyen, 2008). Despite these challenges, migratory movement is still one of the most important ways in which insects respond to hunger stress.

\section{PHYSIOLOGICAL REGULATION OF INSECT ENERGY UNDER STARVATION STRESS}

\section{Carbohydrates}

Carbohydrates are a key source of energy for insects. Carbohydrates, mainly in the form of glycogen, trehalose and glucose, play an important role in energy metabolism and metabolite synthesis (Gaxiola et al., 2005; Kehl and Fischer, 2012). They not only enhance insect hunger resistance, but also play a vital role in other physiological adaptations (Tang et al., 2012b; Chng et al., 2017). Studies have found that starved larvae of $A$. mellifera can still maintain a stable blood sugar trehalose concentration (Wang et al., 2016a).

When the blood sugar content of insects is low, glycogen can be broken down, especially during starvation (Marron et al., 2003; Arrese and Soulages, 2010; Parkash et al., 2012; Tang et al., 2012a; Rovenko et al., 2015). Glucose is an equally important carbohydrate and all sugars are eventually converted to glucose to provide ATP, an energy source and metabolic 
TABLE 1 | Some insect behaviors and physiological adaptions under starvation conditions.

\begin{tabular}{|c|c|c|c|c|c|}
\hline No. & Species name & $\begin{array}{l}\text { Main behavioral } \\
\text { regulation }\end{array}$ & $\begin{array}{l}\text { Molecular and } \\
\text { biochemical regulation }\end{array}$ & $\begin{array}{l}\text { Hunger emergency } \\
\text { response }\end{array}$ & Reference \\
\hline 1 & Drosophila melanogaster & Cannibalism & Trehalose, glycogen & Physiological regulation & $\begin{array}{l}\text { Parkash et al., 2012; } \\
\text { Ahmad et al., } 2015\end{array}$ \\
\hline 2 & Harmonia axyridis & Diapause & $\begin{array}{l}\text { Trehalose, glycogen, } \\
\text { proteins }\end{array}$ & Physiological regulation & $\begin{array}{l}\text { Tang et al., 2014; Shen } \\
\text { et al., 2015; Shi et al., } 2017\end{array}$ \\
\hline 3 & Psacothea hilaris & Enter the pupal stage earlier & Trehalose, glucose & Physiological regulation & Munyiri and Ishikawa, 2005 \\
\hline 4 & Bactrocera dorsalis & Enter the pupal stage earlier & Octopamine & Physiological regulation & $\begin{array}{l}\text { Yang, 2014; Cong et al., } \\
\text { 2015; Chen et al., 2017; } \\
\text { Hou et al., 2017; Li, } 2017\end{array}$ \\
\hline 5 & Apis mellifera L. & $\begin{array}{l}\text { Reduced reproductive } \\
\text { capacity }\end{array}$ & Glycogen & Physiological regulation & Wang et al., 2016a,b \\
\hline 6 & Arma chinensis & $\begin{array}{l}\text { Fecundity and egg } \\
\text { hatchability decrease }\end{array}$ & - & - & Zhang et al., 2017 \\
\hline 7 & Eriosoma lanigerum & $\begin{array}{l}\text { Spawn in the early stages, } \\
\text { migration }\end{array}$ & - & Escape & Chen, 2013 \\
\hline 8 & Mythimna separate & Migration & - & Escape & Li, 1993 \\
\hline 9 & Trogoderma granarium & - & Trehalose, glycogen & Physiological regulation & $\begin{array}{l}\text { Mohammadzadeh and } \\
\text { Izadi, } 2018\end{array}$ \\
\hline 11 & Bombyx mori & Enter the pupal stage earlier & Trehalose, glycogen, lipids & Physiological regulation & $\begin{array}{l}\text { Satake et al., 2000; Chen } \\
\text { and Gu, } 2006\end{array}$ \\
\hline 12 & Manduca sexta & - & Glycogen & Physiological regulation & $\begin{array}{l}\text { Meyer-Fernandes et al., } \\
2000\end{array}$ \\
\hline 13 & Rhodnius prolixus & - & Proteins & Physiological regulation & Paim et al., 2016 \\
\hline
\end{tabular}

intermediate in living cells (Jensen et al., 2015). Trehalose, an important component of insect blood is also known as the "sugar of life" (Shukla et al., 2015). In harsh environments, such as severe cold, high temperature and drought, trehalose accumulates and is used to maintain normal life processes and enhanced survival ( $\mathrm{Yu}$ et al., 2008). Glycogen, glucose and trehalose can be converted into other forms for energy storage and release in insects (Tang et al., 2010). When insects are starved, trehalose is used first as a source of energy (Tang et al., 2014), leading to a rapid decrease in glucose and trehalose in their hemolymph (Satake et al., 2000). Under starvation stress, the trehalose content of Trogoderma granarium larvae was significantly reduced (Mohammadzadeh and Izadi, 2018). In starved $P$. hilaris larvae, glucose levels significantly decreased and the level of trehalose showed an initial decrease, followed by an increase (Munyiri and Ishikawa, 2005). The hunger-tolerance mechanisms of insects differ. For example, the hemolymph glucose concentration of $A$. mellifera was significantly reduced under starvation stress (Buckemüller et al., 2017) whereas the phosphorylase activity of Bombyx mori and Manduca sexta larvae increased and the glycogen content gradually decreased (Meyer-Fernandes et al., 2000; Satake et al., 2000). When the intensity of starvation stress increases, glycogen is converted to trehalose and released into the blood to maintain energy metabolism (Bede et al., 2007). Therefore, as the intensity of starvation increases, the levels of trehalose and glycogen in insects decrease, but trehalose remains at a relatively low and stable concentration (Shi et al., 2017). After relief from hunger stress, the hemolymph glucose levels of insects increase (Sánchez-Paz et al., 2007) and are gradually converted into trehalose and glycogen for storage.
The most important substances that mediate the decomposition of carbohydrates are trehalose synthase (TPS), trehalase (TREH), glycogen synthase (GS), and insulin-like pathway-related genes (Tang et al., 2012b). In H. axyridis exposed to starvation stress, the trehalose level and trehalase activity were significantly lower $8 \mathrm{~h}$ after starvation treatment, but the relative expression of TRE1-1 increased. After 8-24 h of starvation, trehalose was maintained at a high level, but glycogen levels decreased. These results indicate that trehalose plays a key role in the starvation process through molecular and biochemical regulation of trehalose and glycogen metabolism (Tang et al., 2014; Shi et al., 2017). When human blood sugar levels are very low, the body increases the blood sugar concentration by regulating the insulin signaling pathway. For insects, insulin-like signaling pathways in vivo play a similar role in controlling the balance of blood glucose concentrations (Kuhn et al., 2015; Zhai et al., 2015). Similarly, in D. melanogaster and B. mori, a decrease in insulin-like signaling levels regulate the expression of related antimicrobial peptide genes (Becker et al., 2010; Yang et al., 2016; Lebreton et al., 2017). These genes participate in immune regulation and repair of damage and thereby enhance the resistance of insects to starvation (Riddell and Mallon, 2006).

\section{Lipids}

Fat bodies are the main units of lipid storage in insects and their storage function is key for normal life processes (Ballard et al., 2008; Kehl and Fischer, 2012; Park et al., 2013). To combat hunger, stored lipid resources are often used through reduced glucose oxidation and increased fatty acid mobilization and lipid oxidation (Gergs and Jager, 2014; McCue et al., 2015; Wang et al., 2016a). Lipid metabolism in insects is 
mainly regulated by Adipokinetic hormone $(\mathrm{AKH})$, the fat stimulating hormone, which is secreted under low nutrient conditions, thereby leading to lipolysis, glycogenolysis, and sugar and lipid nutrients moving from the fat body into the hemolymph (Kim and Rulifson, 2004; Lee and Park, 2004). $\mathrm{AKH}$, a key regulator of energy-also mobilizes sugar and lipids from insect fat bodies during high-energy activities such as flight and exercise and contributes to the balance of hemolymph sugars, lipids, and carbohydrates (Staubli et al., 2002; Hou et al., 2017). Intensive research has found that the ability of insects to survive starvation is largely dependent on the ratio of triglycerides to lipids in the body (Renault et al., 2002; Ballard et al., 2008; Laparie et al., 2012). When insects fly under starvation conditions, lipids are the main source of energy for the flight muscles (Ryan and van der Horst, 2000). Lipids are, therefore, closely linked to insect movement during starvation. Of course, the use of lipids under starvation stress varies among different insects. Under laboratory starvation conditions, the concentration of lipids in the hemolymph of B. mori increased (Satake et al., 2000) whereas in Pachnoda sinuata (Coleoptera: Scarabaeidae), the lipids in the flight muscles and fat bodies significantly decreased (Auerswald and Gäde, 2000). The beetle Merizodus soledadinus (Coleoptera: Carabidae) significantly increased the hydrolysis of triglycerides during food deprivation which returned to normal levels after feeding (Laparie et al., 2012). This suggests that triglycerides are immediately mobilized to enhance hunger resistance in the event of food shortage.

It is worth noting that moderate hunger leads to the accumulation of fat, which is dependent on the developmental stage of the insect and the state of feeding (Lorenz, 2001). Increased fat mass in insects can increase resistance to hunger, indicating a significant correlation between lipid levels and hunger resistance (Parkash et al., 2014). Pure lipid-based triglycerides are used during starvation (Sinclair et al., 2011) and proteins that are starved by lipid synthesis or degradation are affected by the opposite form. For example, a fatty acid synthase and a glycocholine transfer protein were down-regulated four fold after $4 \mathrm{~h}$ of starvation, while triacylglycerol lipase levels increased 10 fold (Muhlia-Almazán et al., 2005).

\section{Proteins}

A modest decrease in protein content during insect starvation indicates that insects can cope with hunger by using different endogenous reserves (Gäde and Auerswald, 2002; Helland et al., 2003). After starvation, the concentrations of alanine in the flight muscles, lipid bodies, and hemolymph of insects rapidly decline whereas those of proline remain high (Kehl and Fischer, 2012). At the same time, the heat shock proteins 70 (HSP70s) are important stress protectants in $H$. axyridis and Rhodnius prolixus (Hemiptera, Reduviidae) and play a role in adaptation to food deprivation (Shen et al., 2015; Paim et al., 2016). In addition, studies have shown that the positive effects of adult amino acids are limited to females, presumably because their high protein demand significantly changes the catabolic rate (Mevi-Schütz and Erhardt, 2005; Bauerfeind and Fischer, 2009). There is ample evidence that amino acids extracted from protein breakdown are degraded during starvation (Haubert et al., 2005).

\section{Nerve Signals and Hormones}

When insects are stressed by hunger, they initiate a series of anti-starvation mechanisms. These mechanisms include regulating the expression of related genes, synthesizing anti-stress substances and regulating the catabolism of energy substances in the body to maintain normal growth and development (Buckemüller et al., 2017). A study in D. melanogaster found that dG9a (histone methyltransferase) is a key factor in tolerance to hunger stress and is also a key regulator of behavioral strategies under starvation conditions (An P.N.T. et al., 2017; Shimaji et al., 2017). Hunger is a powerful driver of food intake and some neurons, neuropeptides and neurohormones play key roles in behavioral and physiological regulation (Perić-Mataruga, 2006; Jourjine et al., 2016; Mena et al., 2016). At the same time, starvation increases the expression level of SLC5A11 neurons and enhances their excitability by inhibiting the dKCNQ channel, thereby conferring hunger status and promoting feeding and starvation-driven behaviors (Park et al., 2016).

Hunger itself affects stress in insects and the expression of immunity-related genes. Many immunity-related genes, such as interleukin 1- $\beta$, are significantly down-regulated during starvation (Riddell and Mallon, 2006; Buckemüller et al., 2017) leading to lower metabolism followed by a concomitant decline in immunity (Guo et al., 2014). Starvation stress can also significantly up-regulate the expression of two octopamine (OA) receptor genes $(\mathrm{Li}, 2017)$. OA has significant biological effects on the growth and behavior of various arthropods and poor living conditions pose differential consequences on the distribution and content of OA. Hunger not only has an effect on the transcription of the brain and surrounding tissues in Drosophila (Bos et al., 2016; Singh et al., 2018), but also induces autophagy in Drosophila larvae during metamorphosis by inhibiting the PI3KI/AktTor pathway (Riddiford et al., 2000; Wang et al., 2012). Similarly, starvation can also induce autophagy in Spodoptera frugiperda (Lepidoptera: Noctuidae) Sf9 cells (Xie K. et al., 2017). Increased levels of autophagy are usually induced by signals such as starvation, while excessive levels of autophagy can cause autophagic programmed cell death. During starvation, the level of autophagy helps to reduce the level of apoptosis in fat cells, thus playing a protective role in the survival of adipocytes (Otomo et al., 2013; Li et al., 2015).

Dopaminergic signaling pathways and juvenile hormones (JH) are also important stress-resistance substances in insects and play a role in adaptation to hunger stress (Neckameyer and Weinstein, 2005; Lee and Horodyski, 2006). While the former directly affects the metamorphosis and development of insects (Yang, 2014), the latter confers damage protecting (Shi et al., 2016). After starvation treatment, the growth and development of Plutella xylostella (Lepidoptera: Plutellidae) were found to be delayed because the expression of the juvenile hormone acid methyl transferase (JHAMT) candidate gene Px009591 increased and the expression of the juvenile hormone esterase (JHE) gene Px004817 and JHE activity decreased. These changes led to an 
increase in JH levels in insects, which in turn delayed growth and development (Duan, 2016). Similarly, the rate of biosynthesis of M. sexta gradually increased after starvation (Lee and Horodyski, 2006). Telang et al. (2010) also found that JHE mRNA levels in the $4^{\text {th }}$ instar larvae of Aedes aegypti (Diptera: Culicidae) were close to zero after $36 \mathrm{~h}$ of starvation. In addition, when the expression of the hsp18.3 gene of Tribolium castaneum (Coleoptera: Tenebrionidae) was silenced by RNAi technology, the resistance of the starved group was significantly lower than that of the control group (Xie J. et al., 2017). Similarly, a study of three HSP70 genes in $H$. axyridis showed that their relative expression not only increased with increasing temperature, but also at the peak of starvation at $8 \mathrm{~h}$ (Shen et al., 2015). Thus, juvenile hormones and heat shock proteins have a significant effect on insect emergency stress responses.

\section{FUTURE PROSPECTS}

Nutrition plays an important role in the life history of insects, especially as reproduction is influenced by the quality and quantity of food (Fischer et al., 2004). While dietary restrictions can reduce reproductive yield, it can also extend an insect's lifespan (Partridge et al., 2005; Carey et al., 2008). At the same time, insects exposed to starvation or low temperatures may enter a state of diapause. In previous studies, 46 diapauserelated genes were found in Aphidius gifuensis (Hymenoptera: Aphididae) (Huang et al., 2015; An T. et al., 2017) and 443 in Coccinella septempunctata (Coleoptera: Coccinellidae) (Liu et al., 2014; Ren et al., 2015; Qi et al., 2016). These genes are associated with energy demand during diapause and inhibition of metabolism. During diapause and wintering in insects, nutrient levels, amino acid accumulation and transformation and regulatory mechanisms including insulin signaling pathways are similar to those under starvation stress (Hahn and Denlinger, 2007; Huang et al., 2015; Ren et al., 2016; Sinclair and Marshall,

\section{REFERENCES}

Ahmad, M., Chaudhary, S. U., Afzal, A. J., and Tariq, M. (2015). Starvationinduced dietary behaviour in Drosophila melanogaster larvae and adults. Sci. Rep. 5:14285. doi: 10.1038/srep14285

An, P. N. T., Shimaji, K., Tanaka, R., Yoshida, H., Kimura, H., Fukusaki, E., et al. (2017). Epigenetic regulation of starvation-induced autophagy in Drosophila by histone methyltransferase G9a. Sci. Rep. 7:7343. doi: 10.1038/s41598-01707566-1

An, T., Zhang, H. Z., Han, Y. H., Chen, H. Y., and Zhang, L. S. (2017). Transcriptome analysis of diapause-associated genes of Aphidius gifuensis Ashmaed. Chin. J. Biol. Control 33, 604-611. doi: 10.16409/j.cnki.2095-039x. 2017.05.005

Arrese, E. L., and Soulages, J. L. (2010). Insect fat body: energy, metabolism, and regulation. Annu. Rev. Entomol. 55, 207-225. doi: 10.1146/annurev-ento112408-085356

Auerswald, L., and Gäde, G. (2000). Metabolic changes in the African fruit beetle, Pachnoda sinuata, during starvation. J. Insect Physiol. 46, 343-351. doi: 10.1016/ S0022-1910(99)00187-0

Ballard, J. W., Melvin, R. G., and Simpson, S. J. (2008). Starvation resistance is positively correlated with body lipid proportion in five wild caught Drosophila simulans populations. J. Insect Physiol. 54, 1371-1376. doi: 10.1016/j.jinsphys. 2008.07.009
2018). Moderate hunger can also have a positive impact on insects and on pest control. Thus, a systematic examination of behavioral and physiological strategies under starvation stress can provide significant theoretical basis for the development of natural breeding in insects and storage of natural enemy insects for their use in pest control.

Nutritionally challenging situations in environments have evolved insects with diverse adaptive responses to withstand periods of food shortage. In this review we have attempted to showcase the starvation stress physiology of insects with respect to behavioral attributes and physiological regulation. Given their broad range of ecological habitats, insects are suitable and convenient models to evaluate the strategies they employ to cope with starvation. Moreover, starvation stress research in insects offers interesting cues from ecological and evolutionary perspectives that not only govern reproduction, survivorship and cross tolerance to other environmental stressors but also dictate phenotypic plasticity in adjusting development and life histories around nutritionally optimal environmental conditions. Such studies are critical to our understanding of starvation-induced physiological responses that precede death and in extrapolating them to vertebrates.

\section{AUTHOR CONTRIBUTIONS}

B-PZ, Z-JX, KL, and D-WZ conceived and manuscript structure design. B-PZ, Y-LT, and D-WZ wrote the manuscript.

\section{FUNDING}

This work was supported by the National Natural Science Foundation of China (Grant No. 31560511) and Science and Technology Foundation of Guizhou Province [Grant No. QKH.JZ (2014)2014].

Bauerfeind, S. S., and Fischer, K. (2009). Effects of larval starvation and adult dietderived amino acids on reproduction in a fruit-feeding butterfly. Entomol. Exp. Appl. 130, 229-237. doi: 10.1111/j.1570-7458.2008.00814.x

Becker, T., Loch, G., Beyer, M., Zinke, I., Aschenbrenner, A. C., Carrera, P., et al. (2010). FOXO-dependent regulation of innate immune homeostasis. Nature 463, 369-373. doi: 10.1038/nature08698

Bede, J. C., McNeil, J. N., and Tobe, S. S. (2007). The role of neuropeptides in caterpillar nutritional ecology. Peptides 28, 185-196. doi: 10.1016/j.peptides. 2006.08.030

Billings, A. C., Schultz, K. E., Hernandez, E. A., Jones, W. E., and Price, D. K. (2018). Male courtship behaviors and female choice reduced during experimental starvation stress. Behav. Ecol. doi: 10.1093/beheco/ary144

Bos, N., Pulliainen, U., Sundström, L., and Freitak, D. (2016). Starvation resistance and tissue-specific gene expression of stress-related genes in a naturally inbred ant population. R. Soc. Open. Sci. 3:160062. doi: 10.1098/rsos.160062

Buckemüller, C., Siehler, O., Göbel, J., Zeumer, R., Ölschläger, A., and Eisenhardt, D. (2017). Octopamine underlies the counter-regulatory response to a glucose deficit in Honeybees (Apis mellifera). Front. Syst. Neurosci. 11:63. doi: 10.3389/fnsys.2017.00063

Carey, J. R., Harshman, L. G., Liedo, P., Müller, H. G., Wang, J. L., and Zhang, Z. (2008). Longevity-fertility trade-offs in the tephritid fruit fly, Anastrepha ludens, across dietary-restriction gradients. Aging Cell. 7, 470-477. doi: 10.1111/j.14749726.2008.00389.x 
Chang, J. H. (2015). Calculation and comparison of evaluation indexes of insect hunger resistance ability-Taking the calculation of hunger resistance of Nilaparvata lugens at different ages as an example. Jiangsu Agric. Sci. 43, 129-131. doi: 10.15889/j.issn.1002-1302.2015.04.046

Chen, C. H., and Gu, S. H. (2006). Stage-dependent effects of starvation on the growth, metamorphosis, and ecdysteroidogenesis by the prothoracic glands during the last larval instar of the silkworm, Bombyx mori. J. Insect Physiol. 52, 968-974. doi: 10.1016/j.jinsphys.2006.06.011

Chen, E. H., Hou, Q. L., Wei, D. D., Jiang, H. B., and Wang, J. J. (2017). Phenotypes, antioxidant responses, and gene expression changes accompanying a sugaronly diet in Bactrocera dorsalis (Hendel) (Diptera: Tephritidae). BMC Evol. Biol. 17:194. doi: 10.1186/s12862-017-1045-5

Chen, J. J. (2013). Study on the Starvation Endurance Ability of Wooly Apple Aphid. Dissertation for Master's, Northwest A\&F University, Xianyang.

Chng, W. A., Hietakangas, V., and Lemaitre, B. (2017). Physiological adaptations to sugar intake: new paradigms from Drosophila melanogaster. Trends Endocrinol. Metab. 28, 131-142. doi: 10.1016/j.tem.2016.11.003

Cong, L., Jiang, X. Z., Yang, W. J., Xu, K. K., Dou, W., Ran, C., et al. (2015). Identification of ecdysone synthesis pathway genes and analysis on the impact of food deprivation on larvae development of Bactrocera dorsalis hendel. Sci. Agric. Sin. 48, 4469-4482. doi: 10.3864/j.issn.0578-1752.2015.22.008

Duan, D. (2016). Identification and Expression Pattern of JH-Related Genes in Plutella xylostella and Their Responses to External Modulators. Dissertation for Master's, Fujian Agriculture and Forestry University, Fuzhou.

Elkin, C. M., and Reid, M. L. (2005). Low energy reserves and energy allocation decisions affect reproduction by Mountain Pine Beetles, Dendroctonus ponderosae. Funct. Ecol. 19, 102-109. doi: 10.1111/j.0269-8463.2005.00935.x

Feng, Y. Q., Wang, J. L., and Zong, S. X. (2014). Review of insects overwintering stages and cold-resistance strategies. Chin. Agric. Sci. Bull. 30, 22-25.

Fischer, K., O'Brien, D. M., and Boggs, C. L. (2004). Allocation of larval and adult resources to reproduction in a fruit-feeding butterfly. Funct. Ecol. 18, 656-663. doi: $10.1111 / \mathrm{j} .0269-8463.2004 .00892 . \mathrm{x}$

Fujikawa, K., Takahashi, A., Nishimura, A., Itoh, M., Takano-Shimizu, T., and Ozaki, M. (2009). Characteristics of genes up-regulated and down-regulated after $24 \mathrm{~h}$ starvation in the head of Drosophila. Gene 446, 11-17. doi: 10.1016/j. gene.2009.06.017

Gäde, G., and Auerswald, L. (2002). Beetles' choice-proline for energy output: control by AKHs. Compar. Biochem. Physiol. Part B 132, 117-129. doi: 10.1016/ S1096-4959(01)00541-3

García-Roger, E. M., Martínez, A., and Serra, M. (2006). Starvation tolerance of rotifers produced from parthenogenetic eggs and from diapausing eggs: a life table approach. J. Plankton Res. 28, 257-265. doi: 10.1093/plankt/fbi062

Gaxiola, G., Cuzon, G., García, T., Taboada, G., Brito, R., Chimal, M. E., et al. (2005). Factorial effects of salinity, dietary carbohydrate and moult cycle on digestive carbohydrases and hexokinases in Litopenaeus vannamei (Boone, 1931). Comp. Biochem. Physiol. Part A 140, 29-39. doi: 10.1016/j.cbpb.2004. 10.018

Gergs, A., and Jager, T. (2014). Body size-mediated starvation resistance in an insect predator. J. Anim. Ecol. 83, 758-768. doi: 10.1111/1365-2656.12195

Guo, L., Karpac, J., Tran, S. L., and Jasper, H. (2014). PGRP-SC2 promotes gut immune homeostasis to limit commensal dysbiosis and extend lifespan. Cell 156, 109-122. doi: 10.1016/j.cell.2013.12.018

Hahn, D. A., and Denlinger, D. L. (2007). Meeting the energetic demands of insect diapause: nutrient storage and utilization. J. Insect Physiol. 53, 760-773. doi: 10.1016/j.jinsphys.2007.03.018

Haubert, D., Langel, R., Scheu, S., and Ruess, L. (2005). Effects of food quality, starvation and life stage on stable isotope fractionation in Collembola. Pedobiologia 49, 229-237. doi: 10.1016/j.pedobi.2004.11.001

Helland, S., Nejstgaard, J. C., Fyhn, H. J., Egge, J. K., and Båmstedt, U. (2003). Effects of starvation, season, and diet on the free amino acid and protein content of Calanus finmarchicus females. Mar. Biol. 143, 297-306. doi: 10.1007/s00227003-1092-x

Helm, B. R., Rinehart, J. P., Yocum, G. D., Greenlee, K. J., and Bowsher, J. H. (2017). Metamorphosis is induced by food absence rather than a critical weight in the solitary bee, Osmia lignaria. Proc. Natl. Acad. Sci. U.S.A. 114, 10924-10929. doi: 10.1073/pnas.1703008114

Hou, Q. L., Chen, E. H., Jiang, H. B., Wei, D. D., Gui, S. H., Wang, J. J., et al. (2017). Adipokinetic hormone receptor gene identification and its role in triacylglycerol mobilization and sexual behavior in the oriental fruit fly (Bactrocera dorsalis). Insect Biochem. Mol. Biol. 90, 1-13. doi: 10.1016/j.ibmb. 2017.09.006

Huang, C. (2015). Effect of Temperature and Food Stress on Survival, Development and Reproduction of Bactrocera Minax (Enderlein). Dissertation for Master's, Yangtze University, Jingzhou.

Huang, F. X., Jiang, S., Ren, X. Y., An, T., Chen, H. Y., and Zhang, L. S. (2015). Differential expression of proteins associated with lipid metabolism in diapausing Aphidius gifuensis ashmaed. Chin. J. Biol. Control. 31, 811-820. doi: 10.16409/j.cnki.2095-039x.2015.06.001

Jensen, K., Schal, C., and Silverman, J. (2015). Suboptimal nutrient balancing despite dietary choice in glucose-averse German cockroaches, Blattella germanica. J. Insect Physiol. 81, 42-47. doi: 10.1016/j.jinsphys.2015.07.001

Jourjine, N., Mullaney, B. C., Mann, K., and Scott, K. (2016). Coupled sensing of hunger and thirst signals balances sugar and water consumption. Cell 166, 855-866. doi: 10.1016/j.cell.2016.06.046

Kehl, T., and Fischer, K. (2012). Larval starvation reduces responsiveness to feeding stimuli and does not affect feeding preferences in a butterfly. J. Insect Physiol. 58, 1028-1035. doi: 10.1016/j.jinsphys.2012.05.008

Kim, S. K., and Rulifson, E. J. (2004). Conserved mechanisms of glucose sensing and regulation by Drosophila corpora cardiaca cells. Nature 431, 316-320. doi: 10.1038 /nature02897

Kuhn, H., Sopko, R., Coughlin, M., Perrimon, N., and Mitchison, T. (2015). The Atg1-Tor pathway regulates yolk catabolism in Drosophila embryos. Development 142, 3869-3878. doi: 10.1242/dev.125419

Laparie, M., Larvor, V., Frenot, Y., and Renault, D. (2012). Starvation resistance and effects of diet on energy reserves in a predatory ground beetle (Merizodus soledadinus; Carabidae) invading the Kerguelen Islands. Comp. Biochem. Physiol. Part A 161, 122-129. doi: 10.1016/j.cbpa.2011.09.011

Lebreton, S., Carlsson, M. A., and Witzgall, P. (2017). Insulin signaling in the peripheral and central nervous system regulates female sexual receptivity during starvation in Drosophila. Front. Physiol. 8:685. doi: 10.3389/fphys.2017. 00685

Lee, G., and Park, J. H. (2004). Hemolymph sugar homeostasis and starvationinduced hyperactivity affected by genetic manipulations of the adipokinetic hormone-encoding gene in Drosophila melanogaster. Genetics 167, 311-323. doi: 10.1534 /genetics.167.1.311

Lee, K. Y., and Horodyski, F. M. (2006). Effects of starvation and mating on corpora allata activity and allatotropin (Manse-AT) gene expression in Manduca sexta. Peptides 27, 567-574. doi: 10.1016/j.peptides.2005.08.024

Li, C. C., Li, L. Q., Huang, C. X., and Zhang, D. (2015). Autophagy promotes survival of adipose cells by inhibiting apoptosis under in vitro starvation. Chin. J. Pathophysiol. 31, 2228-2232. doi: 10.3969/j.issn.1000-4718.2015.12.019

Li, G. B. (1993). Research overview of Mythimna separate and major progress. Plant Protection. 19, 2-4.

Li, H. M. (2017). Studies on the Physiological Function and Pharmacological Properties of $B d O c t \beta 1 R$ and $B d O c t \beta 2 R$ in Bactrocera dorsalis (Hendel). Dissertation for Master's, Southwest University, Chongqing.

Liu, Y., Zhang, L. S., Chen, H. Y., Huang, F. X., Jiang, S., and Ren, X. Y. (2014). Differential expression of malate dehydrogenase and isocitrate dehydrogenase in diapaused ladybird, Coccinella septempunctata L. Chin. J. Biol. Control. 30, 593-599. doi: 10.16409/j.cnki.2095-039x.2014.05.002

Lorenz, M. W. (2001). Synthesis of lipids in the fat body of Gryllus bimaculatus: age-dependency and regulation by adipokinetic hormone. Arch. Insect Biochem. Physiol. 47, 198-214. doi: 10.1002/arch.1052

Marron, M. T., Markow, T. A., Kain, K. J., and Gibbs, A. G. (2003). Effects of starvation and desiccation on energy metabolism in desert and mesic Drosophila. J. Insect Physiol. 49, 261-270. doi: 10.1016/S0022-1910(02)00287-1

McCue, M. D., Guzman, R. M., Passement, C. A., and Davidowitz, G. (2015). How and when do insects rely on endogenous protein and lipid resources during lethal bouts of starvation? A new application for 13C-breath testing. PLoS One 10:e0140053. doi: 10.1371/journal.pone.0140053

McCue, M. D., Terblanche, J. S., and Benoit, J. B. (2017). Learning to starve: impacts of food limitation beyond the stress period. J. Exp. Biol. 220, 4330-4338. doi: $10.1242 /$ jeb.157867

Mena, W., Diegelmann, S., Wegener, C., and Ewer, J. (2016). Stereotyped responses of Drosophila peptidergic neuronal ensemble depend on downstream neuromodulators. Elife 5:e19686. doi: 10.7554/eLife.19686 
Mevi-Schütz, J., and Erhardt, A. (2005). Amino acids in nectar enhance butterfly fecundity: a long-awaited link. Am. Nat. 165, 411-419. doi: 10.1086/429150

Meyer-Fernandes, J. R., Gondim, K. C., and Wells, M. A. (2000). Developmental changes in the response of larval Manduca sexta fat body glycogen phosphorylase to starvation, stress and octopamine. Insect Biochem. Mol. Biol. 30, 415-422. doi: 10.1016/S0965-1748(00)00015-1

Mohammadzadeh, M., and Izadi, H. (2018). Cooling rate and starvation affect supercooling point and cold tolerance of the Khapra beetle, Trogoderma granarium everts fourth instar larvae (Coleoptera: Dermestidae). J. Therm. Biol. 71, 24-31. doi: 10.1016/j.jtherbio.2017.10.007

Muhlia-Almazán, A., Sánchez-Paz, A., García-Carreño, F., Peregrino-Uriarte, A. B., and Yepiz-Plascencia, G. (2005). Starvation and diet composition affect mRNA levels of the high density-lipoprotein-beta glucan binding protein in the shrimp Litopenaeus vannamei. Compar. Biochem. Physiol. Part B 2142, 209-216. doi: 10.1016/j.cbpc.2005.07.005

Munyiri, F. N., and Ishikawa, Y. (2005). Feeding glucose or sucrose, but not trehalose, suppresses the starvation-induced premature pupation in the yellowspotted longicorn beetle, Psacothea hilaris. J. Insect Physiol. 51, 1005-1012. doi: 10.1016/j.jinsphys.2005.04.015

Neckameyer, W. S., and Weinstein, J. S. (2005). Stress affects dopaminergic signaling pathways in Drosophila melanogaster. Stress 8, 117-131. doi: 10.1080/ 10253890500147381

Nguyen, D. T. (2008). Effects of starvation period on the locomotory response of Rhyzopertha dominica (F.). J. Stored Prod. Res. 44, 100-102. doi: 10.1016/j.jspr. 2007.06.007

Ojima, N., Hara, Y., Ito, H., and Yamamoto, D. (2018). Genetic dissection of stressinduced reproductive arrest in Drosophila melanogaster females. PLoS Genet. 14:e1007434. doi: 10.1371/journal.pgen.1007434

Otomo, C., Metlagel, Z., Takaesu, G., and Otomo, T. (2013). Structure of the human ATG12 ATG5 conjugate required for LC3 lipidation in autophagy. Nat. Struct. Mol. Biol. 20, 59-66. doi: 10.1038/nsmb.2431

Paim, R. M. M., Araujo, R. N., Leis, M., Sant'anna, M. R. V., Gontijo, N.F., Lazzari, C. R., et al. (2016). Functional evaluation of Heat Shock Proteins 70 (HSP70/HSC70) on Rhodnius prolixus (Hemiptera, Reduviidae) physiological responses associated with feeding and starvation. Insect Biochem. Mol. Biol. 77, 10-20. doi: 10.1016/j.ibmb.2016.07.011

Panizzi, A. R., and Hirose, E. (1995). Seasonal body weight, lipid content, and impact of starvation and water stress on adult survivorship and longevity of Nezara viridula and Euschistus heros. Entomol. Exp. Appl. 76, 247-253. doi: 10.1111/j.1570-7458.1995.tb01969.x

Park, J. Y., Dus, M., Kim, S., Abu, F., Kanai, M. I., Rudy, B., et al. (2016). Drosophila SLC5A11 mediates hunger by regulating $\mathrm{K}+$ channel activity. Curr. Biol. 26, 1965-1974. doi: 10.1016/j.cub.2016.05.076

Park, M. S., Park, P., and Takeda, M. (2013). Roles of fat body trophocytes, mycetocytes and urocytes in the American cockroach, Periplaneta americana under starvation conditions: an ultrastructural study. Arthropod Struct. Dev. 42, 287-295. doi: 10.1016/j.asd.2013.03.004

Parkash, R., Aggarwal, D. D., Ranga, P., and Singh, D. (2012). Divergence of larval resource acquisition for water conservation and starvation resistance in Drosophila melanogaster. J. Comp. Physiol. B. 182, 625-640. doi: 10.1007/ s00360-011-0641-8

Parkash, R., Ranga, P., and Aggarwal, D. D. (2014). Developmental acclimation to low or high humidity conditions affect starvation and heat resistance of Drosophila melanogaster. Comp. Biochem. Physiol. Part A 175, 46-56. doi: 10.1016/j.cbpa.2014.05.006

Partridge, L., Piper, M. D., and Mair, W. (2005). Dietary restriction in Drosophila. Mech. Ageing Dev. 126, 938-950. doi: 10.1016/j.mad.2005.03.023

Perić-Mataruga, V., Nenadović, V., and Ivanović, J. (2006). Neurohormones in insect stress: a review. Arch. Biol. Sci. 58, 1-12. doi: 10.2298/ABS0601006P

Qi, X. Y., Ren, X. Y., An, T., Chen, H. Y., Huang, J., and Zhang, L. S. (2016). Transcriptome analysis of diapause-associated genes of Coccinella septempunctata L. J. Environ. Entomol. 38, 238-248. doi: 10.3969/j.issn.16740858.2016.02.3

Ren, X. Y., Qi, X. Y., An, T., Han, Y. H., Chen, H. Y., and Zhang, L. S. (2016). Research on the accumulation, transformation and regulation of nutrients in diapause insects. Chin. J. Appl. Entomol. 53, 685-695. doi: 10.7679/j.issn.20951353.2016.086
Ren, X. Y., Zhang, L. S., Qi, X. Y., An, T., Han, Y. H., and Chen, H. Y. (2015). Metabolic adaption and evaluation of cold hardiness on diapausing ladybird,Coccinella septempunctata L. J. Environ. Entomol. 37, 1195-1202. doi: 10.3969/j.issn.1674-0858.2015.06.11

Renault, D., Hervant, F., and Vernon, P. (2002). Comparative study of the metabolic responses during food shortage and subsequent recovery at different temperatures in the adult lesser mealworm, Alphitobius diaperinus (Coleoptera: Tenebrionidae). Physiol. Entomol. 27, 291-301. doi: 10.1046/j.1365-3032.2002. 00299.x

Riddell, C. E., and Mallon, E. B. (2006). Insect psychoneuroimmunology: immune response reduces learning in protein starved bumblebees (Bombus terrestris). Brain Behav. Immun. 20, 135-138. doi: 10.1016/j.bbi.2005.06.008

Riddiford, L. M., Cherbas, P., and Truman, J. W. (2000). Ecdysone receptors and their biological actions. Vitam. Horm. 60, 1-73. doi: 10.1016/S0083-6729(00) 60016-X

Rotkopf, R., Alcalay, Y., Bar-Hanin, E., Barkae, E. D., and Ovadia, O. (2013). Slow growth improves compensation ability: examining growth rate and starvation endurance in pit-building antlions from semi-arid and hyper-arid regions. Evol. Ecol. 27, 1129-1144. doi: 10.1007/s10682-013-9644-0

Rovenko, B. M., Perkhulyn, N. V., Gospodaryov, D. V., Sanz, A., Lushchak, O. V., and Lushchak, V. I. (2015). High consumption of fructose rather than glucose promotes a diet-induced obese phenotype in Drosophila melanogaster. Comp. Biochem. Physiol. Part A 180, 75-85. doi: 10.1016/j.cbpa.2014.11.008

Ryan, R. O., and van der Horst, D. J. (2000). Lipid transport biochemistry and its role in energy production. Annu. Rev. Entomol. 45, 233-260. doi: 10.1146/ annurev.ento.45.1.233

Sánchez-Paz, A., García-Carreño, F., Hernández-López, J., Muhlia-Almazán, A., and Yepiz-Plascencia, G. (2007). Effect of short-term starvation on hepatopancreas and plasma energy reserves of the Pacific white shrimp (Litopenaeus vannamei). J. Exp. Mar. Biol. Ecol. 340, 184-193. doi: 10.1016/j.jembe.2006.09.006

Sánchez-Paz, A., García-Carreño, F., Muhlia-Almazán, A., Peregrino-Uriarte, A. B., Hernández-López, J., and Yepiz-Plascencia, G. (2006). Usage of energy reserves in crustaceans during starvation: status and future directions. Insect Biochem. Mol. Biol. 36, 241-249. doi: 10.1016/j.ibmb.2006.01.002

Satake, S., Kawabe, Y., and Mizoguchi, A. (2000). Carbohydrate metabolism during starvation in the silkworm Bombyx mori. Arch. Insect Biochem. Physiol. 44, 90-98. doi: 10.1002/1520-6327(200006)44:2<90::AID-ARCH4>3.0.CO;2-0

Shen, Q. D., Zhao, L. N., Xie, G. Q., Wei, P., Yang, M. M., Wang, S. G., et al. (2015). Cloning three Harmonia axyridis (Coleoptera: Coccinellidae) heat shock protein 70 family genes: regulatory function related to heat and starvation stress. J. Entomol. Sci. 50, 168-185. doi: 10.18474/JES14-30.1

Shi, C. H., Hu, J. R., Li, C. R., and Zhang, Y. J. (2016). Research progress in the cold tolerance mechanism of insects under environmental stress. Plant Prot. 42, 21-28. doi: 10.3969/j.issn.0529-1542.2016.06.003

Shi, Z. K., Wang, S., Wang, S. G., Zhang, L., Xu, Y. X., Guo, X. J., et al. (2017). Effects of starvation on the carbohydrate metabolism in Harmonia axyridis (Pallas). Biol. Open 6, 1096-1103. doi: 10.1242/bio.025189

Shimaji, K., Tanaka, R., Maeda, T., Ozaki, M., Yoshida, H., Ohkawa, Y., et al. (2017). Histone methyltransferase G9a is a key regulator of the starvation-induced behaviors in Drosophila melanogaster. Sci. Rep. 7:14763. doi: 10.1038/s41598017-15344-2

Shukla, E., Thorat, L. J., Nath, B. B., and Gaikwad, S. M. (2015). Insect physiological significance and potential applications. Glycobiology 25, 357-367. doi: 10.1093/ glycob/cwu125

Sinclair, B. J., Bretman, A., Tregenza, T. O. M., Tomkins, J. L., and Hosken, D. J. (2011). Metabolic rate does not decrease with starvation in Gryllus bimaculatus when changing fuel use is taken into account. Physiol. Entomol. 36, 84-89. doi: $10.1111 / j .1365-3032.2010 .00765 . x$

Sinclair, B. J., and Marshall, K. E. (2018). The many roles of fats in overwintering insects. J. Exp. Biol. 221:jeb161836. doi: 10.1242/jeb.161836

Singh, S., Gupta, M., Pandher, S., Kaur, G., Rathore, P., and Palli, S. R. (2018). Selection of housekeeping genes and demonstration of RNAi in cotton leafhopper, Amrasca biguttula biguttula (Ishida). PLoS One 13:e0191116. doi: 10.1371/journal.pone.0191116

Staubli, F., Jorgensen, T. J., Cazzamali, G., Williamson, M., Lenz, C., Sondergaard, L., et al. (2002). Molecular identification of the insect adipokinetic 
hormone receptors. Proc. Natl. Acad. Sci. U.S.A. 99, 3446-3451. doi: 10.1073/ pnas.052556499

Tang, B., Chen, J., Yao, Q., Pan, Z., Xu, W., Wang, S., et al. (2010). Characterization of a trehalose-6-phosphate synthase gene from Spodoptera exigua and its function identification through RNA interference. J. Insect Physiol. 56, 813-821. doi: 10.1016/j.jinsphys.2010.02.009

Tang, B., Qin, Z., Shi, Z. K., Wang, S., Guo, X. J., Wang, S. G., et al. (2014). Trehalase in Harmonia axyridis (Coleoptera: Coccinellidae): effects on beetle locomotory activity and the correlation with trehalose metabolism under starvation conditions. Appl. Entomol. Zool. 49, 255-264. doi: 10.1007/s13355014-0244-4

Tang, B., Wei, P., Chen, J., Wang, S. G., and Zhang, W. Q. (2012a). Progress in gene features and functions of insect trehalases. Acta Entomol. Sin. 55, 1315-1321. doi: 10.16380/j.kcxb.2012.11.008

Tang, B., Xu, Q., Zou, Q., Fang, Q., Wang, S., and Ye, G. (2012b). Sequencing and characterization of glycogen synthase and glycogen phosphorylase genes from Spodoptera exigua and analysis of their function in starvation and excessive sugar intake. Arch. Insect Biochem. Physiol. 80, 42-62. doi: 10.1002/arch. 21027

Telang, A., Peterson, B., Frame, L., Baker, E., and Brown, M. R. (2010). Analysis of molecular markers for metamorphic competency and their response to starvation or feeding in the mosquito, Aedes aegypti (Diptera: Culicidae). J. Insect Physiol. 256, 1925-1934. doi: 10.1016/j.jinsphys.2010.08.020

Wang, C. X., Zheng, W. W., Liu, P. C., Wang, J. X., and Zhao, X. F. (2012). The steroid hormone 20-hydroxyecdysone upregulated the protein phosphatase 6 for the programmed cell death in the insect midgut. Amino Acids 43, 963-971. doi: 10.1007/s00726-011-1159-9

Wang, Y., Campbell, J. B., Kaftanoglu, O., Page, R. E. Jr., Amdam, G. V., and Harrison, J. F. (2016a). Larval starvation improves metabolic response to adult starvation in honey bees (Apis mellifera L.). J. Exp. Biol. 219, 960-968. doi: 10.1242/jeb.136374

Wang, Y., Kaftanoglu, O., Brent, C. S., Page, R. E. Jr., and Amdam, G. V. (2016b). Starvation stress during larval development facilitates an adaptive response in adult worker honey bees (Apis mellifera L.). J. Exp. Biol. 219, 949-959. doi: $10.1242 /$ jeb. 130435

Xie, J., Hu, X. X., Zhai, M. F., Yu, X. J., Song, X. W., Gao, S. S., et al. (2017). Characterization and functional analysis of hsp18.3 gene in the red flour beetle, Tribolium castaneum. Insect Sci. 26, 263-273. doi: 10.1111/1744-7917.12543

Xie, K., Wang, L. X., Wang, J., Zhu, L. M., Yin, J. H., Ye, Q. X., et al. (2017). The response of Spodoptera frugiperda sf9 cells to starvation induced autophagy. Acta Agricul. Boreali-simica. 32, 91-95. doi: 10.7668/hbnxb.2017. 03.014

Yang, W. J. (2014). Study on Important Genes in the Biosynthetic and Metabolic Pathways of Chitin and Juvenile Hormone in Bactrocera dorsalis. Dissertation for Master's, Southwest University, Chongqing.

Yang, W. K., Tang, F. F., Liu, Z. H., Zhong, J., and Dong, Z. P. (2016). Effects of starvation on DefensinA and DefensinB expression in silkworm, Bombyx mori. Southwest Chin. J. Agricul. Sci. 29, 3019-3022. doi: 10.16213/j.cnki.scjas.2016. 12.044

Yu, C. H., Lu, D., Lin, R. H., Wang, X. J., Jia, H., and Zhao, F. (2008). Trehalose-the blood sugar in insects. Chin. Bull. Entomol. 45, 832-837.

Zauner, C., Schneeweiss, B., Kranz, A., Madl, C., Ratheiser, K., Kramer, L., et al. (2000). Resting energy expenditure in short-term starvation is increased as a result of an increase in serum norepinephrine. Am. J. Clin. Nutr. 71, 1511-1515. doi: 10.1093/ajcn/71.6.1511

Zhai, Y., Sun, Z., Zhang, J., Kang, K., Chen, J., and Zhang, W. (2015). Activation of the TOR signalling pathway by glutamine regulates insect fecundity. Sci. Rep. 5:10694. doi: 10.1038/srep10694

Zhang, H. P., Pan, M. Z., Yi, Z. J., Zhang, C. H., Guo, Y., Liu, C. X., et al. (2017). Effects of short term starvation on longevity, fecundity and predation of Arma chinensis (Hemiptera: Pentatomidae). Chin. J. Biol. Control. 33, 159-164. doi: 10.16409/j.cnki.2095-039x.2017.02.002

Zhang, X. Y., Zhai, Y. F., Zhuang, Q. Y., Lin, Q. C., Wu, W. H., Tao, M., et al. (2015). Research advance of insect diapause. Shangdong Agric. Sci. 47, 143-148. doi: 10.14083/j.issn.1001-4942.2015.02.034

Zhang, H. H., Chen, J. H., Ji, Q. E., and Luo, M. J. (2015). Overview in the study and application of the influencing factors on oviposition behavior of insects. J. Environ. Entomol. 37, 432-440. doi: 10.3969/j.issn.1674-0858.2015. 02.31

Conflict of Interest Statement: The authors declare that the research was conducted in the absence of any commercial or financial relationships that could be construed as a potential conflict of interest.

Copyright (c) 2019 Zhang, Xiao, Zeng, Li and Tang. This is an open-access article distributed under the terms of the Creative Commons Attribution License (CC BY). The use, distribution or reproduction in other forums is permitted, provided the original author(s) and the copyright owner(s) are credited and that the original publication in this journal is cited, in accordance with accepted academic practice. No use, distribution or reproduction is permitted which does not comply with these terms. 